demonstrated some colourful experiments showing fluorescence and phosphorescence in solids, and energy transfer in solid mixtures; the possible importance of such phenomena in biology was discussed. Dr. R. Hill (Cambridge) followed with an account of recent work on photosynthesis. He pointed out the sequence of biochemical processes in the breakdown and synthesis of carbohydrates, involving phosphorylated intermediates and adenosine triphosphate. His comparison of the structure and properties of chloroplasts and mitochondria led to interesting discussion of the possible influence of physical structure on the chemical processes which these regulate. During the afternoon session Dr. W. A. H. Rushton (Cambridge) gave a stimulating review of recent physiological work on visual pigments, including a recorded demonstration of the electrical response from the optic nerve of a frog on change of illumination, in contrast to the absence of signal during steady illumination. In the final paper, Mr. J. S. Preston (National Physical Laboratory, Teddington) gave an account of methods used for the absolute standardization of light meters. At the conclusion of the papers, a business meeting was held at which it was decided to establish the Photobiology Group on a permanent basis ; to hold two meetings of this kind a year ; and to affiliate with the Comité International de Photobiologie. Further information about future activities can be obtained from Dr. E. M. F. Roe, Chester Beatty Research Institute, Fulham Road, London, S.W.3.

\section{The Woodhull Lecture at the Royal Institution}

The late Miss Z. M. Woodhull, of Norton Park, near Tewkesbury, who was a life-member of the Royal Institution, Albemarle Street, London, gave practical form to her interest in the improvement of racial qualities in future generations and her attachment to the Royal Institution by making a bequest to be used by the Institution for the furtherance of the study of eugenics. The managers of the Royal Institution, as a first step in carrying out Miss Woodhull's wishes, have, after consultation with the trustees of her estate, arranged for lectures to be given from time to time on aspects of eugenics. The first Woodhull Lecture will be delivered at the Royal Institution at 6 p.m. on October 27 by Prof. J. B. S. Haldane, on "The Prospects for Eugenics". He will discuss how the earlier eugenists were over-hopeful as to the possibilities of rapid racial improvement; that the fact of mutation makes the permanent 'purification' of a race impossible with our existing knowledge; how a large reduction in congenital abnormalities may eventually be achieved; and the impact of atomic nuclear reactions upon the study of genetics.

\section{Recent Gifts to the University of Oxford}

THE University of Oxford has announced the receipt of gifts and grants amounting to $£ 100,000$ for a wide variety of purposes. The largest is $£ 52,000$ from the Rockefeller Foundation towards the cost of providing research laboratory facilities and equipment for the use of the regius professor of medicine at the Radeliffe Infirmary. Arthur Guinness, Son and Co., Ltd., is increasing to $£ 4,000$ a year the sum of $£ 2,500$ a year for seven years which they previously covenanted to pay for the three research fellowships in microbiological chemistry in the Department of Biochemistry. Other sums include 2,000 dollars from the National Council to Combat Blindness, Inc., towards the purchase of apparatus for research at the Nuffield Laboratory of Ophthalmology; 10,000 dollars from the International Bank for Reconstruction and Development for a survey of British experience in the management of capital investment overseas, which is to, be carried out at Nuffield College; $£ 4,850$ from the Nuffield Foundation for research work in the Department of Human Anatomy ; $£ 700$ a year for seven years from Major H. W. Hall to make possible the purchase of an optical spectrograph for use in the research laboratory for archæology and the history of art; and $£ 1,000$ a year for seven years from the British Oxygen Co., Ltd., for the continuation of low-temperature research in the Clarendon Laboratory.

\section{Preservation of the Sheld-Duck in Germany}

IN the annual report for 1954 of the International Committee for Bird Preservation (pp. 66; from the British Museum (Natural History), 1955 ; $2 s .6 d$. net) a noteworthy example is given of the help afforded to bird-lovers by one of the Armed Services. When Heligoland was given up as a bombing range by the Royal Air Force in 1951, it was agreed with the Government of the German Federal Republic that the range should be transferred to the Grosse Knechtsand in the mouth of the Elbe. As a result, large numbers of sheld-duck were being destroyed, and there was a real possibility that the species would be exterminated. The matter was referred to the Secretary of State for Air, who was informed that the sheld-duck use the sand-banks of Grosse Knechtsand during their moulting season in July and August; the duck are flightless during this season, which is thus the season of danger. Almost immediately the Secretary of State announced that "new arrangements will be made for the use of the range during the next moulting season. Only practice bombs will be dropped containing only a small charge to set off a smoke marker, which will mean that there will be no blast effect. The Royal Air Force will co-operate with ornithologists under arrangements to be made with the British Section of the International Committee, to inspect the range before and after bombing has taken place to establish its effect on the Sheld-Duck. By these measures there is every hope that in the future the species will be able to moult without being seriously molested".

\section{Protection from Radioactive Isotopes}

THE increased applications of radium sources and the change in the maximum permissible dose have necessitated a revision of the radium protection code given in Handbook 23 of the United States National Bureau of Standards. Furthermore, the nuclear reactor has made available other high-energy, relatively long-lived, gamma-ray emitters-for example, cobalt-60 and cæsium-137, which are now coming into general use. The National Committee on Radiation has accordingly issued Handbook 54, "Protection against Radiations from Radium, Cobalt-60, and Cesium-137", prepared by Subcommittee 9, which supersedes the previous Hand. book. The general principles outlined, though referring specifically to the three sources, are also applicable to other gamma-ray emitters and should prove useful as a preliminary guide until these other emitters are given separate treatment. Industrial applications are not considered; the medical appli- 